\title{
The impact of the March 10, 2009 dust storm on meteorological parameters in central Saudi Arabia
}

\author{
Abdullrahman H. Maghrabi \\ National Centre For Mathematics and Physics, King Abdulaziz City For Science and Technology, Riyadh, Saudi \\ Arabia \\ *Corresponding author. Tel: +966-501051884, Fax: +966-14813521, E-mail. amaghrabi@kacst.edu.sa
}

\begin{abstract}
Dust particles play an important role in air quality and environmental health. They affect both solar and terrestrial radiation by scattering and absorption and are therefore considered to be a significant climateforcing factor. Dust storms are natural hazards that affect daily life for an interval ranging from a few hours to a few days, and they are a very frequent phenomenon in Saudi Arabia, especially in the pre-monsoon season.

On 10th March 2009 a widespread and severe dust storm event that lasted several hours struck Riyadh $\left(24.91^{\circ}\right.$ $\mathrm{N}, 46.41^{\circ} \mathrm{E}, 764 \mathrm{~m}$ ) and represented one of the most intense dust storms experienced in Saudi Arabia in the last two decades. In this study, the effect of this dust storm on meteorological parameters was investigated. These parameters are relative humidity, air temperature, visibility and atmospheric pressure. Around noon local time on the event day, with the arrival of the dust plume, there were dramatic changes in weather conditions. Air temperature dropped by about $6{ }^{\circ} \mathrm{C}$, relative humidity increased dramatically reaching a value of $33 \%$. The visibility deteriorated dramatically to a value of $1 \mathrm{~m}$. These results also, show that the effect of this storm was associated with an increase in both atmospheric pressure and relative humidity as well as a r eduction in temperature and visibility for the two days following the storm in comparison with conditions before the storm. The impact of several other dust storms on meteorological parameters during the year of 2009 were investigated and compared to the March 10th storm. It was found that this storm had a greater effect on the meteorological variables than the other storms.
\end{abstract}

Keywords: Dust Storm, Riyadh, Temperature, Solar Radiation

\section{Introduction}

Atmospheric aerosols are linked to the climate system and to the hydrologic cycle. Depending on their composition, atmospheric aerosols can absorb solar radiation in the atmosphere, producing further cooling of the surface and warming the atmosphere. Dust particles affect both solar and terrestrial radiation and are thus considered a significant climate-forcing factor and an important parameter in radiation budget studies [1]. The net effect of atmospheric aerosols is to cool the planet by reflecting incoming solar radiation. One of the major problems associated with dust storms is the considerable reduction of visibility that limits various activities, increases traffic accidents, and may increase the occurrence of vertigo in aircraft pilots [2]. Other environmental impacts include reduced soil fertility at the source area, damage to crops, a reduction of solar radiation, and, consequently, a reduction in the efficiency of solar devices, damage to telecommunications and mechanical systems, dirt, and air pollution. In addition, aerosols have a significant impact on hum an health. Goudie[3] recently provided an up-to-date and comprehensive review on dus $t$ storms and their significance for many fields.

The frequency of dust-storm occurrence in Saudi Arabia is at a maximum during the premonsoon (March-May) season, when dust aerosols are transported by south-westerly winds from the arid and semi-arid regions around the Arabian Sea.

In Saudi Arabia, dust storms are considered among the most severe environmental problems. Several investigators have studied desert dust in Saudi Arabia [4]. Most of the previous studies have used either surface or satellite observations to characterise the large-scale dust loading of the atmosphere over the Arabian Peninsula. However, almost nothing has been 
done to study the effect of these dust storms on meteorological parameters and solar and infrared radiation in this region.

On the 10th of March 2009, a dramatic windstorm moved over Riyadh that was accompanied by a strong dust storm. This short-lived but intense dust storm caused a widespread, heavy dust load, greatly affected visibility and air quality, and caused a total airport shutdown as well as damage to buildings, vehicles, power poles and trees throughout the city of Riyadh. This storm was massive enough to be seen clearly from outer space and is considered to be one of the heaviest recorded dust storms in the last two decades. The outbreak of the dust storm was associated with a cold frontal passage that coincided with the propagation of a preexisting synoptic-scale upper tropospheric jet stream over the northern and central parts of Saudi Arabia.

An investigation of the impact of this storm on solar and infrared radiation will be presented in another paper. This paper studies the impact of this severe storm on $\mathrm{m}$ eteorological parameters and shows the variability of these parameters due to the storm.

\section{Experimental Site and data:}

The study area of Riyadh lies in the central region of the Arabian Peninsula at $24^{\circ} 43^{\prime} \mathrm{N} ; 46^{\circ}$ $40^{\prime} \mathrm{E}, 764 \mathrm{~m}$ a.s.l. Riyadh is the capital of Saudi Arabia and its largest city; its population is 4500000 according to the 2005 census. It is a purely urbanised area and is one of the most polluted areas in the Kingdom because it is surrounded by industrial areas and traffic arterials, with the natural environment of the Empty-Quarter Desert lying beyond. The arid conditions prevailing at this site are responsible for large seasonal temperature differences, providing cool winters and very hot summers. The area experiences extremely low humidity, particularly in the summer. The climate of the region exhibits four dominant seasons each year: winter (December-February), pre-monsoon (March-May), monsoon (June-August), and post-monsoon (September-November). The pre-monsoon season, during which the present case study was conducted, is characterised by frequent dust storms and long dry spells.

Standard meteorological observations such as air temperature, relative humidity, and cloud information were used in the current study. These data were obtained using Riyadh Airport records provided by the Presidency of Meteorology and Environment.

\section{Results and Discussion}

\subsection{Event Description}

For the purpose of clarification the discussion of results will include the behaviour of the considered variables two days before and two days after the storm along with the event day. These will be referred as pre-event, post-event and the event day respectively.

The hourly values of four meteorological variables; relative humidity $(\mathrm{RH})$, temperature $(\mathrm{T})$, visibility (vis), and atmospheric pressure (P) for March 8-12, 2009, are plotted in Figure 1. As shown in Figure 1a, both $\mathrm{T}$ and $\mathrm{RH}$ reveal a diurnal cycle throughout, displaying a trend opposite to what one would expect. Visibility was in the $8-10 \mathrm{~km}$ range on the $8^{\text {th }}$ and $9^{\text {th }}$ of March and on the morning of the $10^{\text {th }}$, which is the normal maximum visibility found in Riyadh at this time of the year. The atmospheric pressure shown in Figure 1b shows a less clear diurnal cycle with some variability from one hour to the next on each day. Through most of the period from the morning of the 8 th of March until the morning on the $10^{\text {th }}$, wind 
directions were consistently southerly. W ind speeds increased during this period from $\sim 10$ $\mathrm{m} / \mathrm{s}$ on the $8^{\text {th }}$ to $\sim 20 \mathrm{~m} / \mathrm{s}$ on the $9^{\text {th }}$.

On the day of the event, before the arrival of the storm, the weather was stable; T was $\sim 28{ }^{\circ} \mathrm{C}$, $\mathrm{P}$ was $939.8 \mathrm{hPa}, \mathrm{RH}$ was $10 \%$, and the local wind was relatively light towards the south. Around noon local time, with the arrival of the dust plume, there were dramatic changes in weather conditions. T he wind swung to a northerly direction and wind speed rapidly increased to a maximum of $30 \mathrm{~ms}^{-1}$.
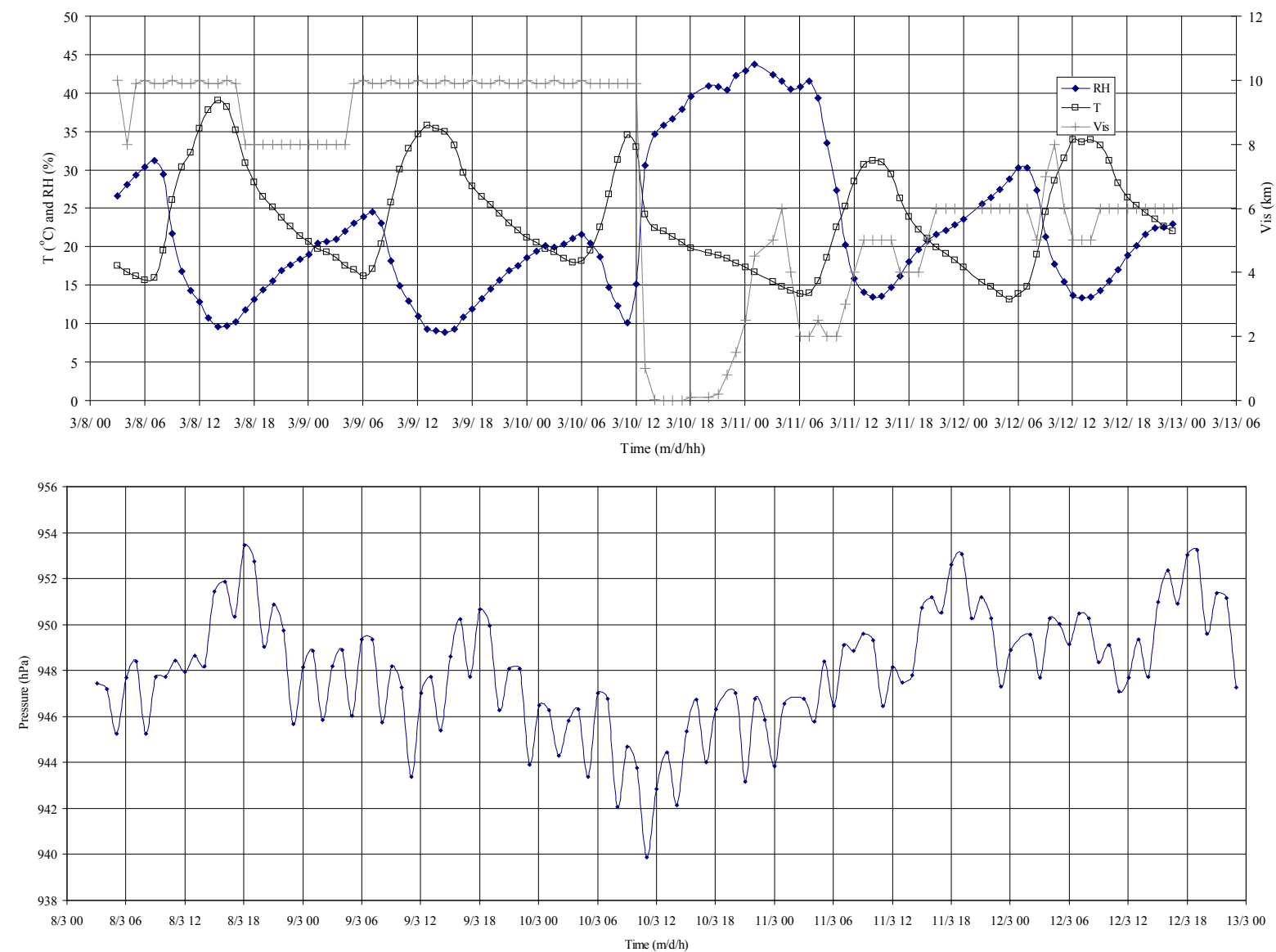

Fig. 1. Day-to-day variations of meteorological parameters (a) relative humidity ,air temperature, and visibility ; and(b) atmospheric pressure for the period from March 8th to March 12th 2009.

Because of the wind change and dust storm, T dropped by about $6{ }^{\circ} \mathrm{C}$ within an hour to reach $22{ }^{\circ} \mathrm{C}$. The temperature continued to decrease until it reached the daily minimum of about 14 ${ }^{\circ} \mathrm{C}$ at 07:00 a.m. on the 11 th. The air temperature then resumed its normal daily cycle, although temperatures remained cool on the 11 th with a maximum of only $23{ }^{\circ} \mathrm{C}$. It is likely that this reduction in the daytime temperature was caused by the reduced heating near the surface resulting from shortwave energy extinction by the additional aerosol loads arriving with the storm on the 10th. Relative humidity, on the other hand, increased dramatically with the arrival of the dust storm, reaching a maximum of $44 \%$ at 01:00 on the 11th. The change in relative humidity is partly due to the cooler air temperatures but is also likely due to the moisture brought to the region by the storm. The visibility deteriorated dramatically with the arrival of the dust storm and then remained around $1 \mathrm{~m}$ for the 3 hours following the event. It then increased to $6 \mathrm{~km}$ by 03:00 on the 11th. After another decrease to $\sim 2 \mathrm{~km}$ in the early 
hours of the morning, it rose to between $5 \mathrm{~km}$ and $6 \mathrm{~km}$ and stayed around this mark for the rest of the period considered.

Several investigations on the dust storms in the Arabian Gulf and adjacent Gulf countries [5] and other places around the world [6] have reported similar variations and characteristic changes in meteorology.

\subsection{Comparisons with other events}

Table 1 shows a list of seven storm events during 2009. It summarises the change of the four meteorological parameters during these events. T hese changes represent the difference between the measured value immediately before the event and the maximum and minimum values reached immediately due to the event. In the last column, the time of maximum change occurs after the arrival of the storm is provided. Three of these events occurred in the premonsoon season, two in spring, one in summer and one in winter. In the last row of the table, the changes in the meteorological parameters for the $10^{\text {th }}$ of March are summarised. Apart from the 18/9 event, the ranges of the changes in both atmospheric pressure and air temperature are confined between $2-4 \mathrm{hPa}$ and $2-3{ }^{\circ} \mathrm{C}$, respectively. The drop in the visibility varies between a minimum of 4 to a maximum of $8 \mathrm{~km}$. The maximum changes in the relative humidity occurred on $4 / 6$ and $18 / 9$, followed by that on $20 / 5$. For the events on $19 / 3$ and 6/10, the RH dropped by -7 and -5 respectively. This drop may be due to the characteristics of the dry air mass that brought the storm to the study region. The $4 / 6$ event is considered the strongest of the seven events. For this event, two hours after the storm, RH and atmospheric pressured increased by $10 \%$ and $3 \mathrm{hPa}$; temperature and visibility dropped by $3^{\circ} \mathrm{C}$ and $8 \mathrm{~km}$, respectively. Comparisons between the $10^{\text {th }}$ of March event and the seven other storm events showed, with the exception of the atmospheric pressure, that the changes in the meteorological variables are higher for the $10^{\text {th }}$ March. In addition, although the two hours after the event on the $10^{\text {th }}$ are considered to be relatively short, dramatic changes occurred during this time.

Table 1 shows the difference between the meteorological variables before the storm and after the storm for the storm event in 2009. The last column is the time when maximum change occurred after the arrival of the storm

\begin{tabular}{cccccc}
\hline DAY/MONTH & $\Delta$ VIS $(\mathrm{KM})$ & $\Delta \mathrm{T}\left({ }^{\mathrm{O}} \mathrm{C}\right)$ & $\Delta \mathrm{P}(\mathrm{HPA})$ & $\Delta \mathrm{RH}(\%)$ & $\begin{array}{c}\text { TIME OF } \\
\text { MAX. } \\
\text { (HOURS) }\end{array}$ \\
\hline $20 / 5$ & 4 & 2 & 3 & 9 & 2 \\
$28 / 5$ & 7 & 3 & 2 & 7 & 3 \\
$4 / 6$ & 8 & 3 & 3 & 10 & 2 \\
$19 / 3$ & 8 & 3 & 2 & -7 & 2 \\
$6 / 10$ & 5 & 2 & 4 & -5 & 2 \\
$28 / 2$ & 6 & 2 & 3 & 9 & 3 \\
$18 / 9$ & 5 & 4 & 5 & 10 & 2 \\
$\mathbf{1 0} / 3$ & $\mathbf{9 . 9}$ & $\mathbf{6}$ & $\mathbf{4}$ & $\mathbf{2 5}$ & $\mathbf{2}$ \\
\hline
\end{tabular}

The effect of different aerosol loads on bot h the spectral and broadband solar radiation components have been investigated extensively both experimentally and theoretically by several researchers. It has been found that the aerosols may reduce the solar radiation by as much as 50\% [7]. Additionally, it was found that dust storms severely affect meteorological variables. Their impact on these variables is different and becomes severe in some cases, 
such as the one presented in this paper. M oreover, because several models have been developed to predict the solar radiation components (e.g., global and diffuse), it is important to consider the impact of such transient and severe events and study their effects to produce the appropriate predictability.

\section{Conclusion}

On 10 March 2009, a severe and extensive dust storm event struck Riyadh and lasted for several hours. The impact of this event on ground-based measurements of meteorological parameters was investigated. These parameters are relative humidity, air temperature, visibility and atmospheric pressure. The analysis for the behaviour of the considered variables two days before and two days after the storm along with the event day were conducted and presented.

The investigations show significant changes in all of the measured parameters as a result of this event. Around noon local time on the event day, with the arrival of the dust plume, there were dramatic changes in weather conditions. Air temperature dropped by about $6{ }^{\circ} \mathrm{C}$, relative humidity increased dramatically reaching a value of $33 \%$. The visibility deteriorated dramatically to a value of $1 \mathrm{~m}$. These results also, show that the effect of this storm was associated with an increase in both atmospheric pressure and relative humidity as well as a reduction in temperature and visibility for the two days following the storm in comparison with conditions before the storm. Comparisons between this storm event and seven other reported events that occurred in the same year showed that this event was the most extreme and the most severe.

\section{References}

[1] A. Jayaraman, Lubin, D., Ramachndran, S., Ramanathan, V., Woodbridge, E., Collins W. and Zalupuri, K. S.. Direct observation of aerosol radiative forcing over the tropical Indian Ocean during the Jan.- Feb. 1996 pr e-INDOEX cruise. J. Geophys. Res. 1998, 103,13827-13836.

[2] H. Kutiel, and Furman, H.,. Dust storms in the Middle East: Sources of origin and their temporal characteristics. Indoor and Built Environment, 2003, 12(6),419-426

[3] A.S., Goudie, Dust storms: Recent developments. Journal of Environmental Management, 2009,90,89-94.

[4] B. H. Alharbi, and Moied, K. 2005. R iyadh air quality report (1999-2004), King Abdulaziz City for Science and Technology, No. 279-25-ER.

[5] D. L. McNaughton, Possible connection between anomalous anticyclones and sandstorms. Weather, 1987, 42 (1),8-13.

[6] P. M., Pauley, Baker, N. L. and Barker, E. H., An Observational Study of the "Interstate 5" Dust Storm Case; Bulletin of the American Meteorological Society, 1996, 77 ( 4), 693-720.

[7] K.V.S., Badarinath, Kharol, S.K, , Kaskaoutis, D.G., and Kambezidis , H.D. 2007. Case study of a dust storm o ver Hyderabad area, India: Its impact on s olar radiation using satellite data and ground measurements; Science of the Total Environment 384 :316-332. 